The other half of Puinta Monroy

PALABRAS CLAVE · VIVIENDA INCREMENTAL · HÁBITAT RESIDENCIAL. POLITICA HABITACIONAL

KEYWORDS · INCREMENTAL HOUSING · RESIDENTIAL HABITAT. HOUSING POHCY

\section{RESUMEN}

La propuesta incremental de Elemental, diseñada para lograr una transformación de la imagen de la vivienda social en Chile, busca resolver a través de un nuevo modelo de vivienda diversas problemáticas asociadas a la organización de la demanda, la calidad de los espacios y la construcción del conjunto, mediante una política de bajo costo pero de alta producción en torno a nuevas soluciones.

Esta operación permite realizar una reflexión en torno a cómo el proyecto de arquitectura se ha ido integrando al contexto urbano y social. Un contexto que en primera instancia fue diseñado en base a un ideal de usos del espacio público y privado, que se contrapone con la llegada del habitante y las transformaciones sucesivas que van ocurriendo en su entorno, generando nuevas necesidades y expectativas que es necesario abordar.

\section{ABSTRACT}

The incremental proposal of Elemental, designed to achieve a transformation of the image of socia housing in Chile, seeks to solve various problems through a new housing model, associated to issues of organization of demand, of quality of spaces and of construction of the whole, under a policy of low cost, high production midst new solutions.

This allows a reflection on how the project of archictecture has been inteorated into the urban and social context which was first desioned based on an ideal of uses of public and private space that contrasts with the arrival of the inhabitant and the successive transformations that are occuring in their surrounding, in response to their future needs and expectations.

\title{
La otra mitad de la Quinta Monroy*
}

\author{
YESSENIA MILLONES SEGOVIA** · Santiago, Chile · yesseniamillones@gmail.com
}

\section{CONTEXTO HISTÓRICO}

La política habitacional de los últimos 50 años en nuestro país está asociada a la labor desarrollada por el Ministerio de Vivienda y Urbanismo, que desde su creación en 1965, busca "responder a la necesidad de los distintos estratos para un mejor acceso a la vivienda para las familias de bajos ingresos, que representa el 70\% de la población" (MINVU, 1997, p. 4). Esta meta cuantitativa, que buscaba disminuir el déficit habitacional en el país, dio paso a la creación del sistema de subsidio a la demanda, momento en que el Estado asume un rol gestionador de la demanda y proveedor de subsidios (Haramoto et al, 1997). Bajo estas condiciones, se entregan la totalidad de funciones al sector privado, convirtiendo a la vivienda en un objeto transable en el mercado, centrando los esfuerzos en la disminución del déficit habitacional, motivo por el cual se ha generado un creciente deterioro de la calidad residencial (Fadda \& Ducci, 1993), ya que no se consideran las diversas relaciones físicoespaciales, psicosociales y político-económicas que se desarrollan en el tiempo.
La producción media de nuevas viviendas desde este momento, no destaca significativamente en cuanto a propuestas de diseño residencial y urbano que logren una conformación de hábitat residencial en todas sus dimensiones, permitiendo el desarrollo de las familias en torno a la escala de vivienda, barrio y ciudad. Por el contrario, se construye una imagen de vivienda estigmatizada y segregada de las actividades y equipamientos de la ciudad.

No obstante lo anterior, destaca por sobre la oferta tradicional del mercado inmobiliario, el caso de la propuesta urbano-arquitectónica inicial de Elemental. Se trata de una propuesta de vivienda evolutiva que nace en el año 2003, bajo una acción sistemática en el ámbito de proyectos de vivienda social, que involucró distintos actores del mundo privado y público, bajo un proyecto común, llevando a cabo la construcción del conjunto Quinta Monroy ubicado en la ciudad de lquique, en el norte de Chile.

** Arquitecta (2017) y diplomada en Hábitat Residencial en Contextos de Vulnerabilidad Social (2015) por la Facultad de Arquitectura y Urbanismo de la Universidad de Chile. 

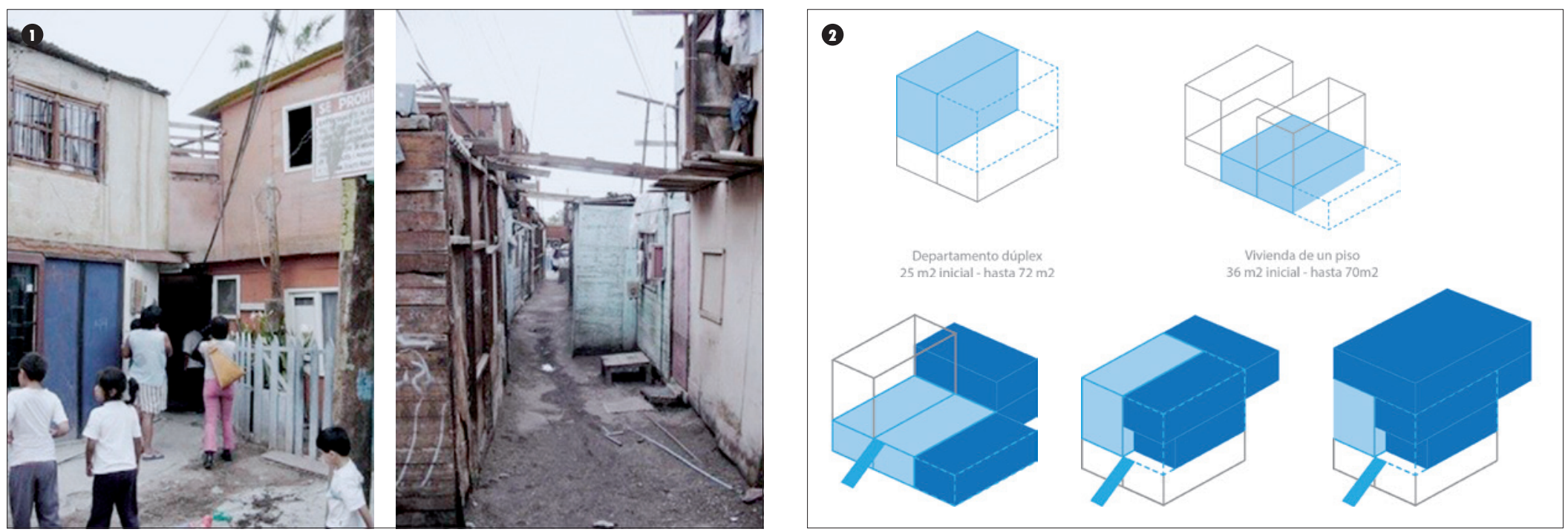

Este hecho marca un punto de inflexión en el desarrollo de lo que se venía realizando hace décadas en cuanto a la producción de vivienda social. En base a una propuesta equilibrada entre calidad y cantidad, se diseña un modelo que ha sido replicado en diferentes ciudades del país y también a nivel internacional. Sin embargo, poco se sabe de su evolución en el tiempo, si ha mejorado o no la calidad de vida de sus habitantes, cómo la gestión previa, durante y posterior a su entrega ha influido en su situación actual y cómo estas soluciones entregadas podrían tener una mayor replicabilidad, considerando lo positivo y negativo de lo desarrollado hasta ahora. Esta reflexión es fundamental, teniendo en cuenta que la vivienda es la base de la conformación del hábitat residencial, condicionando el desarrollo que pueden vivir las familias en el tiempo. Esto, considerando el cambio radical que pueden sufrir las propuestas en contraste con la entrega original, en relación a las superficies construidas, los espacios comunes, la localización, su contexto social y urbano, factores determinantes al momento de pensar un proyecto y su durabilidad en el tiempo, sin el deterioro que se ha presentado en la mayoría de la vivienda social entregada comúnmente.

\section{EL PROYECTO}

El crecimiento poblacional y desarrollo económico-laboral en la ciudad de lquique, provocó en los años ochenta, que fuera la actividad informal la responsable de satisfacer a la demanda de vivienda, dando paso a campamentos en los cuales el hacinamiento, la delincuencia y los bajos niveles de habitabilidad fueron problemáticas cotidianas.

En este período se forma el campamento Quinta Monroy, terreno perteneciente a Ernesto Monroy, quien administra el sitio, permitiendo que las familias lo ocupen para instalar piezas de emergencia en condiciones de habitabilidad mínima, sin servicios básicos, en un escenario en el que el hacinamiento por allegados volvía aún más crítica la situación de estos pobladores. Es a partir de la intervención de Chile Barrio que se contacta con la oficina Elemental, que venía desarrollando tres ideas claras en torno al diseño de vivienda: primero, configurar una tipología que permitiera lograr altas densidades, para ser económicamente viable; segundo, una construcción de baja altura, en función del análisis de las tipologías desarrolladas previamente y sus problemáticas; y tercero, considerar procesos de ampliación, entregando la mitad de la vivienda, la parte más difícil de construir por los habitantes (Aravena \& lacobelli, 2012).

Con el modelo propuesto, una de las principales motivaciones apunta a que la vivienda funcione como una inversión para familias que vivían en condiciones mínimas, de manera tal que la propiedad entregada se valorizara en el tiempo, convirtiéndose en un patrimonio familiar, considerando que el subsidio habitacional es entregado por el Estado solo una vez en la vida. Esto, sumado a un diseño arquitectónico que entrega una vivienda con los mismos parámetros de la clase media, permitiendo a las familias obtener beneficios a partir de esta propuesta habitacional.

Dentro de los límites existentes, se buscaban cuatro objetivos claros: la radicación de las familias en áreas urbanas consolidadas, la construcción progresiva sin deterioro del barrio, la seguridad y economía de las ampliaciones y el diseño con participación de la comunidad. Gracias a esta radicación de las familias, el acceso a la ciudad pasa a ser una de sus principales cualidades, respondiendo con una solución de difícil resolución en el marco de una política habitacional que hasta hoy no cuenta con una planificación de localización de vivienda social ni con una regulación de suelo urbano. 
Con el panorama existente en el mercado inmobiliario, que privilegiaba alejar y achicar, debido a que el subsidio para vivienda social era solo de 300 UF, las empresas buscaban terrenos baratos y construían menor cantidad de metros cuadrados (Aravena \& lacobelli, 2012). Pero la oferta, simplificada a una vivienda aislada en lote, viviendas en fila o los blocks de departamentos, no entregaban una solución a la problemática de la Quinta Monroy. Además, existía la experiencia de propiedades que por su ampliación irregular, no conservaban las condiciones iniciales de vivienda, y se deterioraban con el tiempo. Debido a esta razón es que el análisis del conjunto, se enfoca en revisar las dimensiones territoriales en sus distintas escalas urbanas, socioculturales y político-económicas, para determinar si el modelo cumplió con todo aquello que trata de evitar el diseño proyectual.

\section{LA OTRA MITAD}

En el contexto mencionado, y a partir de la propuesta de Elemental, surgen interrogantes respecto a si se ha logrado la conformación de un hábitat residencial que permita la mantención de la vivienda y su entorno, considerando el proceso de consolidación posterior a la entrega de las viviendas. En función de las respuestas que entregan sus habitantes y mediante la observación en terreno, se evidencia la carencia de un enfoque multidimensional a largo plazo que integrará a los diversos actores en las etapas del proceso habitacional, y de esta manera contribuir al desarrollo de la colectividad en beneficio de las propias familias.

A partir de las condiciones presupuestarias iniciales, el proyecto entregó las viviendas con recintos abiertos, sin divisiones internas y sin terminaciones, tal como se muestra en los planos e imágenes. Es decir, se entregó la mitad de una vivienda básica, traspasando toda la responsabilidad de modificaciones posteriores a cada familia, con la libertad para adaptarse según sus necesidades. Esta particularización atendió a las diferencias familiares, manifestadas
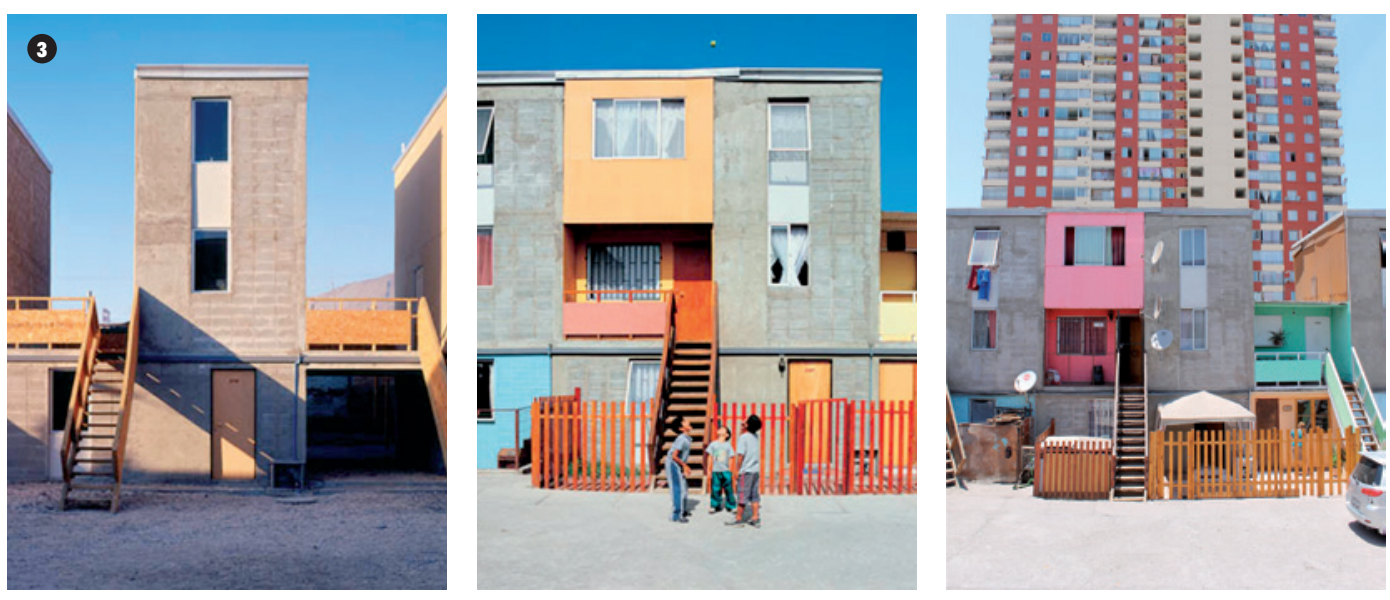

en las distintas decisiones de modificaciones de las viviendas, cuestión que a su vez afecta las condiciones de habitabilidad y calidad de vida en el tiempo.

Por una parte, el desarrollo de la ciudad de lquique, su crecimiento poblacional, han permitido que en las inmediaciones al conjunto hoy exista una alta demanda por la construcción de vivienda en altura. Esta situación se ha transformado en ofertas de compra para las familias de la Quinta Monroy, que en el caso de una vivienda dúplex, ampliada a $72 \mathrm{~m}^{2}$-lo máximo propuesto inicialmente-, no permite a la familia comprar una nueva propiedad de similares características en el sector. Las ofertas varían de acuerdo a la calidad de construcción de las ampliaciones y a la ubicación dentro del conjunto, generando un foco de interés inmobiliario que podría derivar en una gentrificación de las familias para de esta manera proyectar una mayor rentabilidad del terreno.

Esta situación se ve afectada por dos ámbitos. En primer lugar, si bien la propuesta permite la construcción de vivienda social en centros urbanos, con acceso a servicios y equipamiento en el entorno inmediato, existen problemas en el proceso de construcción de comunidad y la infraestructura asociada a esta. Por ejemplo, el espacio correspondiente a patios comunitarios hoy en día es objeto de conflicto social, producto de la priorización de demandas individuales -estacionamiento de vehículos o ampliaciones de la vivienda fuera de los límites establecidos. De esta manera se dificulta la construcción de un espacio común, de encuentro, que favorezca las relaciones sociales y que potencien la comunidad. Por el contrario, a partir de la obtención de la vivienda no ha existido un nuevo proyecto común ni apoyo político-económico que permita el fortalecimiento a nivel comunitario, que pueda desencadenar un sentimiento de apego y arraigo por el lugar que se habita.

Por otro lado, la propuesta de vivienda evolutiva transfiere a las familias la tarea de construir la segunda mitad de su vivienda, ya que el presupuesto entregado priorizó la entrega de una mitad de buena calidad y la compra del terreno. Si bien es cierto esta responsabilidad entregada a las familias otorga la libertad de construir de acuerdo a las necesidades específicas de cada grupo familiar, el contexto actual da cuenta de diversos resultados. Están aquellas familias de 4 a 5 personas que no pudieron construir la otra mitad durante varios años, habitando en los $25 \circ 32 \mathrm{~m}^{2}$ iniciales. A su vez, existen familias que lograron una construcción progresiva de acuerdo a sus recursos económicos, cuestión que se refleja en las diferentes calidades materiales de las ampliaciones y en las distintas superficies de extensión, incluyendo por cierto ampliaciones 
4. Situación actual ampliaciones. Fotografía de la autora, 2016.

5. Evolución vivienda 1. Elaboración propia, 2016.

6. Vivienda 1. Fotografía de la autora, 2016.

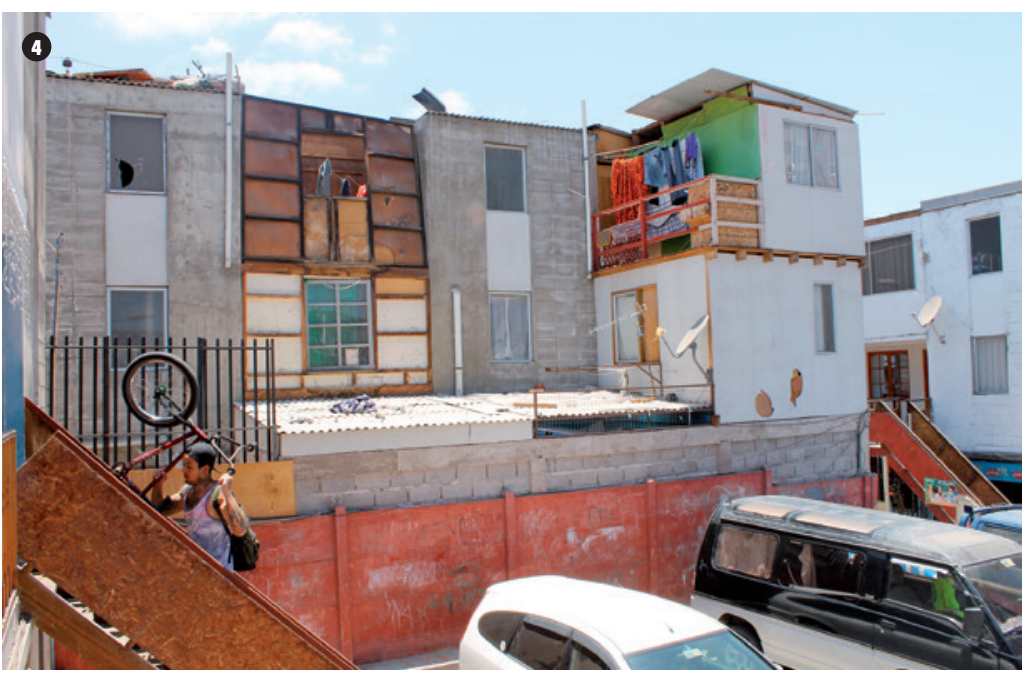

que exceden los límites inicialmente proyectados. Ampliaciones con un bajo estándar de construcción, que han deteriorado progresivamente la calidad arquitectónica inicial y la imagen de conjunto.

Como casos de estudio, la vivienda 1 identifica a una familia para la cual fue esencial poder ampliarse fuera de los límites establecidos y construir un cuarto piso. En esta vivienda habita el propietario con su familia y la hermana de este también con su familia, que por razones económicas se trasladó a la vivienda. Para esta familia, es fundamental el espacio disponible, ya que al ser muchos integrantes requieren de un mayor espacio y así cautelar la condiciones de privacidad. Este dúplex está ubicado en el patio que fue destinado para la comunidad aymara y a pesar de ser uno de los patios más organizados desde un comienzo, con el tiempo se ha debilitado su uso, debido a la llegada de nuevos arrendatarios y al traslado de familias que han decidido vender su vivienda para irse a la zona de Alto Hospicio, privilegiando una propiedad con mayor superficie. Uno de los problemas que presenta esta vivienda, como se repite en algunas otras, es que el segundo piso cuenta con un muro ciego en su parte posterior, debido a que fue cedido para una ampliación de primer piso, por lo que la calidad de
(3)

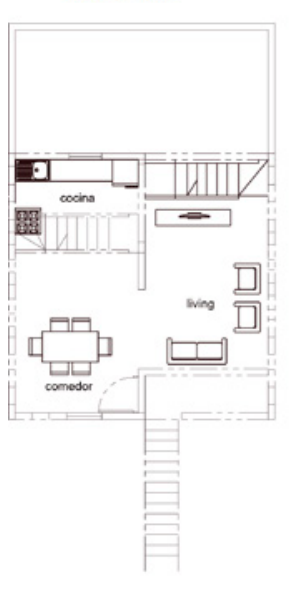

Planta $3^{\circ}$ piso

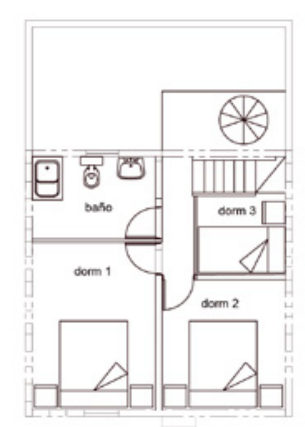

Planta $4^{\circ}$ piso

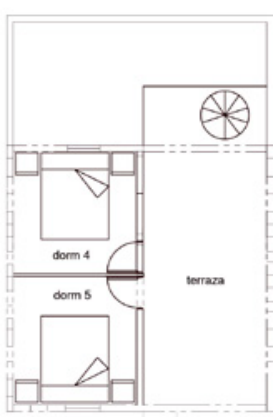

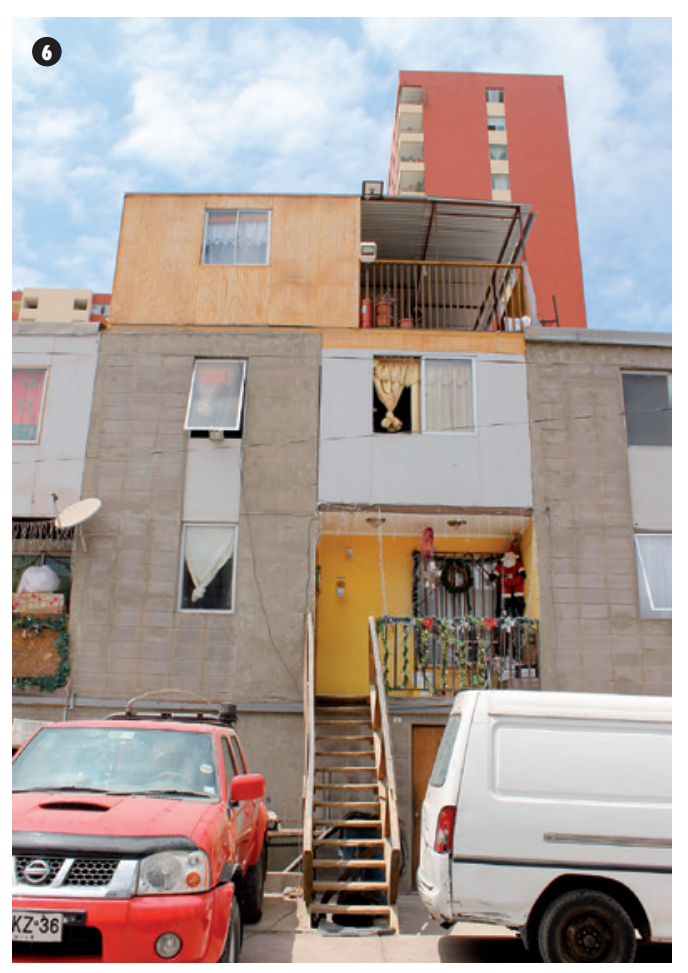

le permita comprar una vivienda en la ciudad. Este dúplex, al estar ubicado en calle Salvador Allende, posee vista al mar. Por último, respecto al estado actual de los patios comunes, el propietario comenta que "la relación entre 
7. Evolución vivienda 2. Elaboración propia, 2016.

8 y 9. Vivienda 2. Fotografía de la autora, 2016.

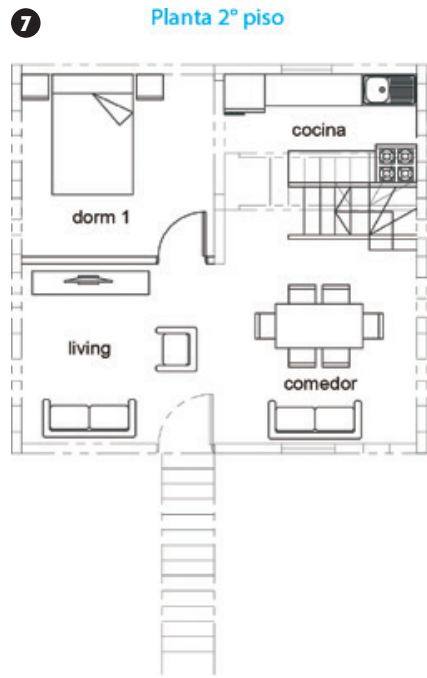

vecinos ya no existe, les entregaron la vivienda y después nunca más hubo organización" [1]

En función de lo expuesto, es posible plantear que para no generar un hábitat abstracto y deshumanizado, en necesario que las escalas de este (vivienda, entorno inmediato, conjunto habitacional, barrio y contexto urbano) sean parte de un sistema. Un sistema con múltiples interacciones e interrelaciones, que requieren de un trabajo en conjunto, multidisciplinario, permitiendo la incorporación de diferentes áreas en el desarrollo y construcción de la nueva vivienda. Por otra parte, es importante que este apoyo no solo esté presente en la etapa previa y entrega de las viviendas, sino que sea un seguimiento constante, especialmente cuando se realiza un esfuerzo mayor por llevar a cabo proyectos que como el caso de Quinta Monroy, cuya situación actual no representa la imagen de conjunto que se pensó lograr. Es necesario dejar de considerar a la vivienda como un mero objeto, situando su producción en un contexto que considere la dimensión social, cultural y humana implicada. Asimismo, se deben
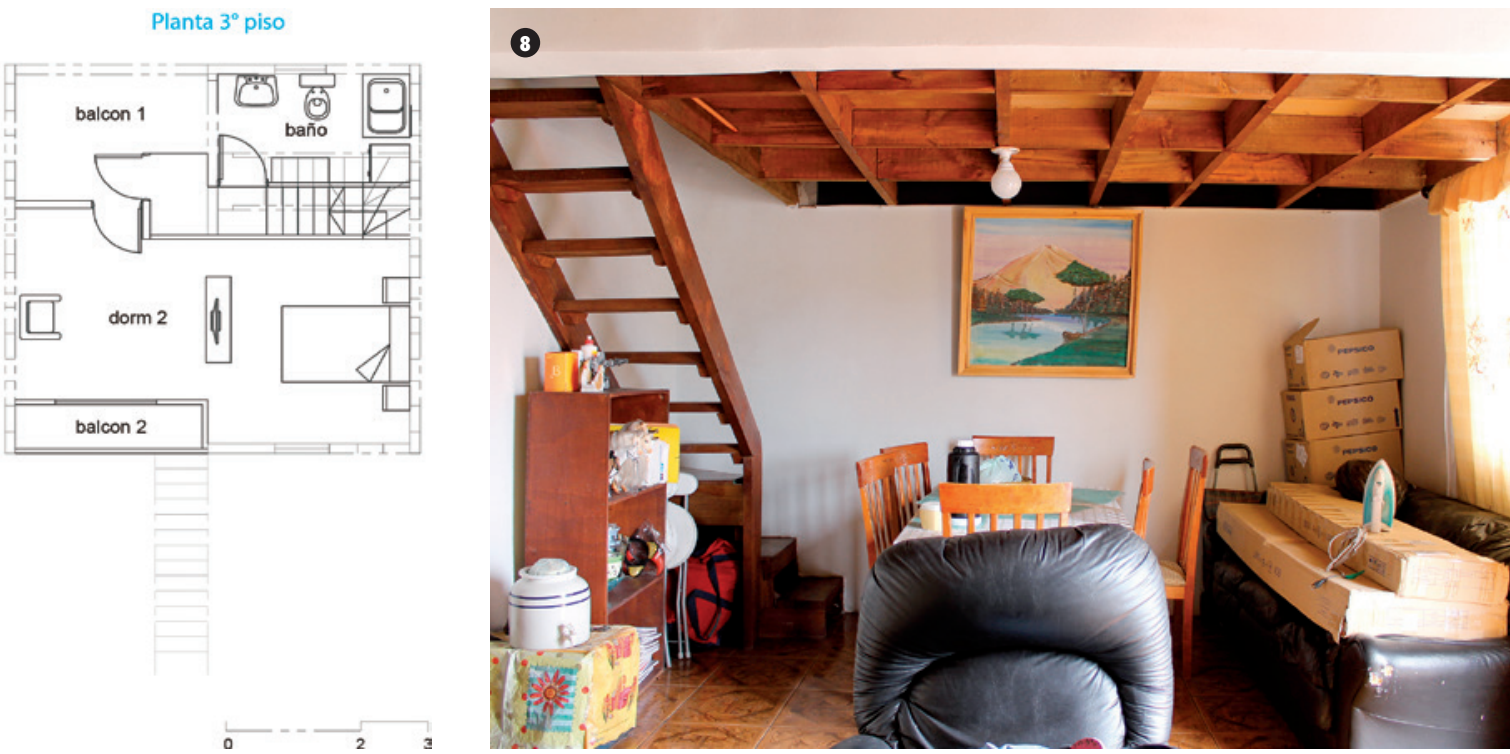

considerar las diferentes escalas de intervención, la vivienda como unidad y su entorno inmediato, el barrio y su conformación de conjunto habitacional, la ciudad dentro de una región, la dimensión política y económica de esta, potenciando el desarrollo y la organización social a una escala local, fortaleciendo las potencialidades que se encuentran en cada sector, generando un cambio social a la espera de una mejora en la calidad de vida a largo plazo.

La tipología diseñada para Quinta Monroy, centrada en la repetición de un modelo para lograr la ubicación de la mayor cantidad de familias posibles, revela una cierta racionalidad de un diseño arquitectónico que logra construirse con un límite presupuestario, pero que deja de lado su relación con el contexto de barrio y urbano donde se inserta.

Estas soluciones arquitectónicas, demuestran que no se trata solamente de una cuestión de diseño, pues para entregar mayor calidad y una buena localización, la vivienda, debe incorporar

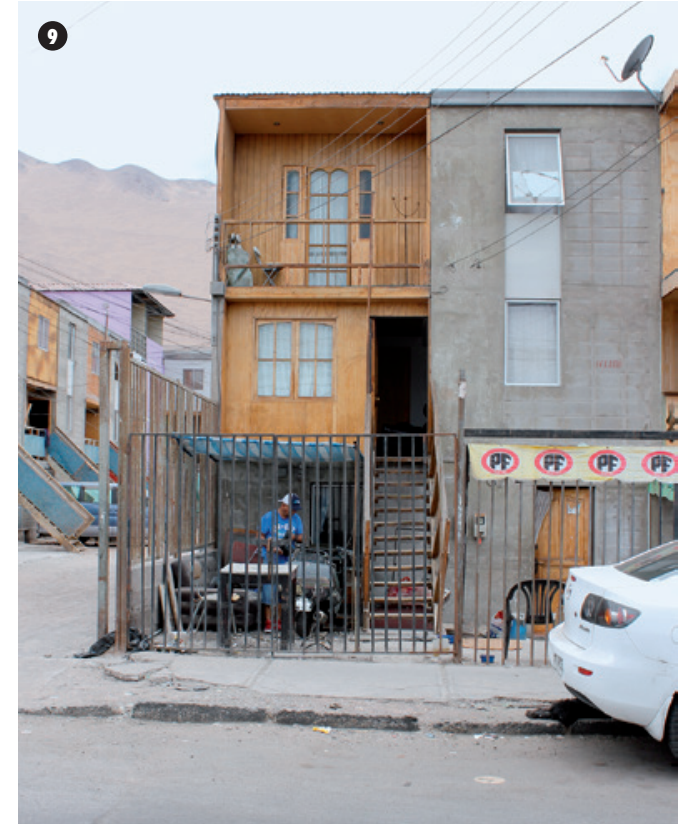

el ámbito social y político. Los conjuntos habitacionales deben tener apoyo en el tiempo para mantener la calidad y de esta manera evitar un deterioro progresivo, convirtiéndose en una verdadera solución para familias más vulnerables del país.

[1] Entrevista realizada en terreno con vecino del conjunto, 2015. 
10 y 11. Espacios no consolidados. Fotografía de la autora, 2016.
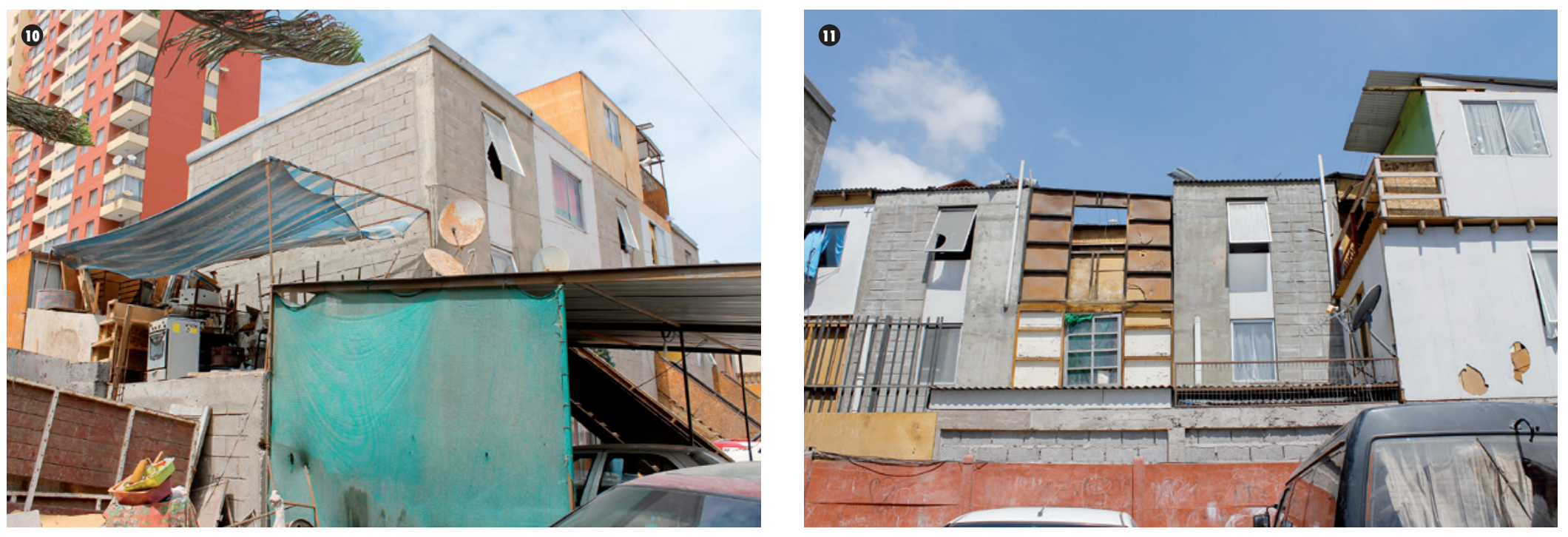

\section{REFERENCIAS BIBLIOGRÁFICAS}

Aravena, A. \& lacobelli, A. (2012). Manual de vivienda incremental y diseño participativo. Ostfildern: Hatje-Cantz.

Ducci, M. E. (1997). "Chile, el lado obscuro de una política de vivienda exitosa". EURE, Revista Latinoamericana de Estudios Urbanos y Regionales, 23(69), 99-115.
Fadda G. y Ducci M. E.(1993) "Políticas de desarrollo urbano y vivienda en Chile: interrelaciones y efectos". En Chile: 50 años de vivienda social. 1943-1993. Valparaíso: ed. Bravo H. y Martínez C.

García Huidobro, F.; Torres, D. \& Tugas, N. (2008). El tiempo construye. El proyecto experimental de vivienda (PREVI) de Lima: génesis y desenlace. Barcelona: Gustavo Gili.
Haramoto, E. (1995). Apuntes de trabajo. Estándares y otros términos relacionados. Archivo INVI.

Haramoto, E.; Jadue, D. \& Tapia, R. (1997).

"Programa de viviendas básicas en la Región Metropolitana. 1990-1995: un análisis crítico desde una perspectiva global". Revista de Arquitectura, 8(9), 32-37.

Pelli, V. S. (2007). Habitar, participar, pertenecer Acceder a la vivienda, incluirse en la sociedad. Buenos Aires: Nobuko. 